\title{
DIVERSIDADE CULTURAL E RESISTÊNCIA: AS MULHERES MANAUARAS E A EDUCAÇÃO DAS CRIANÇAS PEQUENININHAS*
}

Vanderlete Pereira da Silva

\section{Introdução}

Este estudo é resultado de uma pesquisa de doutorado, iniciado em 2016, no Programa de pós-graduação da Faculdade de Educação da Unicamp, vinculada ao grupo de pesquisa GEPEDISC, linha - Culturas Infantis. A pesquisa foi realizada na cidade de Manaus e teve como objetivo conhecer como as mães manauaras educam e cuidam das crianças pequenininhas. As interrogações tinham como parâmetro a Lei de Diretrizes e Bases da Educação Nacional, LDB 9.394/96, na qual ficou estabelecido que a Educação Infantil, creche e pré-escola são a primeira etapa da Educação Básica, acompanhada do avanço das matrículas para a população infantil de 0 a 5 anos e 11 meses nos estados brasileiros e, por fim, a atuação das mulheres no mundo do trabalho em uma cidade industrializada, com importante polo industrial.

O levantamento das matrículas em creche e cruzamento com a população infantil nas regiões brasileiras apontam para números díspares, demonstrando diferenças significativas entre elas. Com a análise dos números, problematizei o que ocorre numa cidade com intensa atividade industrial como a cidade de Manaus, para que haja um distanciamento tão grande entre as vagas e a quantidade de crianças? Onde ficam e com quem ficam as crianças? Há pressão local para ampliação de vagas?

As problematizações, que resultaram no projeto de pesquisa, são decorrentes das minhas inquietações como professora da rede pública, desde a Educação Infantil e posteriormente como professora universitária e da militância na área, no Movimento Interfórum de

*DOI - 10.29388/978-65-86678-02-4-0-f.221-240 
Educação Infantil do Brasil - MIEIB e Campanha Nacional pelo Direito à Educação, ambos movimentos sociais que defendem o direito das crianças à educação. Como objetivo geral, a partir do problema formulado, defini: investigar elementos sociais, culturais e políticos da realidade, que pudessem ser tomados como representativos das concepções a respeito de educar e cuidar de crianças, presentes nas alternativas criadas pelas mães, na perspectiva de compreender a falta de creche pública em Manaus.

No desdobramento do objetivo geral, estabeleci como objetivos específicos: conhecer e descrever as alternativas encontradas pelas mães para educar e cuidar das crianças de 0 a 3 anos em bairros desprovidos de creches públicas; relacionar os conhecimentos das mães quanto ao direito à creche com a luta pela garantia da vaga dos filhos e filhas pequenininhos/as; analisar as percepções das mulheres quanto ao atendimento das crianças em creches públicas; identificar aspectos que possam compreender as alternativas utilizadas pelas mães para o cuidado e a guarda das/os filhas/os em detrimento da luta pela vaga na creche, observando se as alternativas encontradas são iguais tanto para as meninas quanto para os meninos.

Optei pelos estudos decoloniais como base teórica, na perspectiva de ruptura com a matriz colonial do saber, por conter uma forma transgressora de pensar, desvinculada do pensamento e das práticas eurocêntricas. Iniciei com Quijano (2005), a partir do conceito de colonialidade do poder, descrito pelo autor como parte constituidora da Modernidade, responsável pela continuidade do processo de dominação imperialista.

A perspectiva foi conhecer os efeitos da colonialidade e sua complexa estrutura que, segundo Mignolo (2010), se estende para o controle da economia, da autoridade, da natureza e dos recursos naturais, do gênero e da sexualidade, da subjetividade e do conhecimento. Conhecendo os efeitos da colonialidade, poderia relacioná-los posteriormente às formas de educar e cuidar das crianças pequenininhas na cidade de Manaus e, assim, descrevê-las. 
$\mathrm{Na}$ análise do problema, encontrei os vestígios do modo de operar da colonialidade, que atuam para frear e não expandir a solidariedade entre os/as colonizados/as, atribuindo aspectos de homogeneização que atingem também o feminismo, de forma a agir desde a subjetividade e intersubjetividade das/dos colonizadas(os), escamoteando as diferenças em relações sociais complexas, por concentrar tantas e diferentes etnias, como é o caso do contexto investigado.

Como o problema elaborado passava pela discussão de gênero, recorri às autoras decoloniais feministas, a fim de aprofundar a análise a respeito da relação entre colonialidade e gênero. Neste capítulo, enfatizo a produção de duas autoras decoloniais que busquei para dar conta das reflexões que intencionava produzir.

A primeira autora decolonial da qual me aproximei foi Lugones $(2008 ; 2014)$, pela abordagem que considero ponto de partida para entender as questões de gênero entre os colonizados. Para Lugones, embora os homens tenham sidos submetidos ao mesmo processo de exploração que as mulheres durante o período da colonização, foi construída uma relação de poder, de superioridade e dominação por parte destes, que gerou desigualdade entre os gêneros, fator necessário para as inovações nas relações de poder que foram emergindo na nova configuração social. Segundo Lugones (2008), foi estruturado um Sistema Colonial de Gênero, que não foi aprofundado pelas/os pesquisadoras(es) decoloniais, por isso também a opção por suas produções.

A segunda pesquisadora é Rita Laura Segato, que difere do pensamento de Lugones quanto à origem do patriarcado, trazendo questões importantes acerca da violência contra as mulheres e a relação entre gênero e a estruturação da hegemonia capitalista. Enquanto para Lugones (2008), o patriarcado é decorrente do processo de colonização, assim como gênero e raça são invenções do sistema moderno/ colonial, para Segato (2014), nas sociedades indígenas já havia um patriarcado de baixa intensidade, que se aprimorou e fortaleceu no sistema colonial.

No percurso metodológico, utilizei a pesquisa de campo e, para recolhida de dados, entrevistei doze mulheres, com idade entre 20 e 39 
anos, mães de crianças de 0 a 3 anos, moradoras de um bairro com número expressivo de crianças e sem nenhuma creche. Além das entrevistas, utilizei nas análises as conversas informais realizadas com mulheres indígenas de diferentes etnias, mães de crianças pequenininhas que vivem na cidade de Manaus e fazem parte da Associação de $\mathrm{Mu}$ lheres Indígenas do Alto Rio Negro. A hipótese inicial do estudo era que as mães manauaras, ascendentes da cultura indígena, têm outra forma de cuidar e educar as/os filhas/os, que exclui a ida das crianças a creches. O Censo de 2010 revelou que a população do estado do Amazonas é formada por 5,2\% de indígenas ${ }^{1}$. Na cidade de Manaus, um percentual de $0,22 \%$ da população se autodeclarou indígena (IBGE, 2010).

A imersão no tema me levou a refletir se a Constituição Federal Brasileira de 1988, que insere a Educação Infantil como primeira etapa da Educação Básica, inaugurando um novo olhar sobre a educação das crianças pequenas no país e os debates para a construção da legislação, considerou as diferenças culturais que caracterizam as regiões brasileiras, sobretudo as influências dos povos originários, que expressam formas particulares da educação das crianças. Assim, a ideia inicial de pensar a exclusão das crianças pequenininhas das creches, como fato isolado, deu espaço a uma investigação mais ampla da situação, que, me parece, tem raízes bem mais profundas do que o simples observar dos números, não revela, por isso mais difícil de ser percebido e combatido.

1 De acordo com o Censo de 2010, no Brasil, a população indígena corresponde a 896,9 mil pessoas, desse total, 20,4\% vivem no estado do Amazonas. São 95.215 homens e 88.299 mulheres, sendo que 53.985 vivem no estado, no entanto, fora de terras indígenas, embora a Constituição de 1988, no caput do artigo 231, garanta o direito às terras originariamente ocupadas e a demarcação, sob a responsabilidade da União. Barata $(2018$, p.507), explica que O pluralismo jurídico parece estar contido na letra da lei, mas a realidade social enseja questionar-se o alcance desse avanço constitucional, haja vista que nas Disposições Constitucionais Transitórias fixou-se em cinco anos o prazo para que todas as terras indígenas no Brasil fossem demarcadas, e o prazo não se cumpriu. As demarcações ainda são um assunto pendente. 


\section{$\mathrm{Na}$ integração dos povos, a violência contra as mulheres como princi- pal estratégia}

O enfrentamento das mulheres às variadas e perversas faces da violência, presentes no Brasil de hoje, ocorre na Amazônia desde a invasão portuguesa. Os registros históricos ilustram a forma como os colonizadores descreviam e tratavam as mulheres que aqui já habitavam, e da violência que utilizaram para submetê-las aos seus interesses (TORRES; SANTOS, 2011; SANTOS, 2005).

Importante ressaltar que, quando nos referimos à mulher brasileira, além da singularidade construída na diversidade das experiências de vida, é preciso considerar as especificidades do processo de colonização a que fomos submetidas, que faz com que tenhamos lutas distintas, nas diferentes regiões brasileiras. Como afirma Lima (1999, p.6), "Em contraste com outras regiões do Brasil, a colonização da Amazônia incluiu políticas para integrar (ou seja, escravizar, estimular casamentos mistos e "civilizar") a população indígena à sociedade colonial."

Os registros históricos demonstram que a Amazônia foi povoada às custas da violência contra as mulheres indígenas, cujos corpos expostos como mercadorias foram colocados à disposição dos interesses sexuais e econômicos dos homens brancos. As mulheres que habitavam a região foram vistas pelos colonizadores como as parideiras que produziriam os novos escravos, mais tarde transformados em vassalos do rei $^{2}$, para trabalhar e manter os privilégios da Coroa portuguesa nas terras invadidas (TORRES, 2008; TORRES; SANTOS, 2011; COSTA, 2005). Sampaio (2009), explica que:

Em princípio, os novos vassalos, recém-liberados da escravidão, seriam os responsáveis pela garantia da posse dos territórios disputados com a Espanha, os habitantes das povoações e, por fim,

\footnotetext{
${ }^{2}$ Em 1755, foi criada o Diretório dos Índios, passando a vigorar em 1757 no Maranhão e Grão-Pará e, em 1758, vigorou em todo o Brasil até 1798. O Diretório foi a legislação que alterou a condição indígena de escravo, transformando-os, em vassalos do rei de Portugal.
} 
os trabalhadores preferenciais (e, no mais das vezes, exclusivos) para atender às demandas da produção agropecuária e das empresas de coleta de produtos da floresta - “drogas do sertão" que davam vida à economia regional no correr do século XVIII. Fazer com que um número cada vez maior de índios reconhecesse a autoridade real, na condição de súdito, era objetivo a ser perseguido com todo o empenho possível pelos administradores coloniais na região. (SAMPAIO, 2009, p.28)

Torres (2008) descreve o papel que cumpriu a Igreja Católica em sua aliança com a monarquia portuguesa, para proteger seus domínios, continuamente ameaçados. Como forma de povoar a região Nor te do Brasil, incentivaram os "casamentos" de homens vindos de Portugal com as mulheres indígenas das diversas etnias.

Desta forma, a imagem construída pelo europeu, desde sua chegada, no tocante aos povos da Amazônia, foi repercutindo e se atualizando com as novas formas de exploração da força de trabalho, sobretudo das mulheres. As marcas dos costumes europeus e a estética trazidos pelos colonizadores, acompanhadas dos valores patriarcais, violaram costumes, crenças e valores mantidos pelos antigos habitantes, que têm ressonâncias na vida cotidiana das mulheres amazonenses, ainda hoje.

Nesse sentido, busquei compreender como a colonialidade de gênero opera, na perspectiva de reunir subsídios teóricos para entender quais são as particularidades da mulher manauara que se reverberam na atualidade, incidindo nas formas de cuidar e educar das crianças pequenininhas. As questões de gênero pareciam desde o início da pesquisa como centrais no estudo, em conjunto com as especificidades do histórico local e a interseccionalidade com classe social, raça e etnia. Junto aos estudos acerca da colonialidade de gênero, fiz uma retomada da história da ocupação da Amazônia, observando as formas de exploração das mulheres amazônidas, visando identificar pontos de conexão com a educação das crianças pequenininhas na contemporaneidade. 
As leituras a respeito de colonialidade de Aníbal Quijano (2005, 2014), Mignolo (2003, 2005, 2017), posteriormente de Lugones $(2008 ; 2014)$ e Segato $(2003,2012,2014)$ abriram novas e importantes perspectivas de análises acerca da exclusão das crianças pequenininhas do direito à educação. Compreendi que as provocações que me levaram à construção do problema da pesquisa eram somente uma ponta do emaranhado de fios que acenavam despretensiosamente, mas que, aos poucos, revelaram suas conexões e complexidade. Foi esse emaranhado da colonialidade que segui como fio condutor, para pensar a creche ou a falta dela inserida no contexto da modernidade.

Assim, sob o viés étnico, suplantado pela modernidade, procurei entender a formulação da legislação brasileira, quando trata da creche como primeira etapa da Educação Básica. A legislação passa por cima das diferenças étnicas da formação do povo brasileiro, em que a cultura dos povos originários é colocada como algo à parte, numa espécie de ruptura brusca com a força que emana da ancestralidade para instauração do "novo". $\mathrm{Na}$ análise sobre o direito de minorias na Constituição de 1988 e o pluralismo jurídico, Joaquina Barata (2018 p. 503) apresenta a seguinte crítica, que faz referência à questão que problematizava:

O direito estatal revelou-se na história do Brasil insuficiente e incompleto para regular a vida social de um país que se originou de uma invasão e da conquista territorial de extensa área originalmente ocupada por uma pluralidade de etnias indígenas. Além disso, após o chamado "descobrimento", grande quantidade de migrantes, de início escravizados e mais tarde oficialmente libertos, originados do continente africano, passou também a compor a riqueza étnica do país.

Desta forma, no caso do cuidado e educação das crianças pequenininhas, considerando a pluralidade étnica, a legislação parece mais excludente, deixando de fora as formas de educar e cuidar dos povos originários, presente nas práticas cotidianas das mães manauaras. Mesmo em se tratando da cidade de Manaus, onde o percentual de pessoas que se autodeclaram indígenas seja de 0,22\% (IBGE, 2010), há um passado, não muito distante, que está presente na memória e nas 
manifestações culturais do povo amazonense, que não pode ser substituído, como ilustra Mignolo:

A partição imperial da África entre os países ocidentais no final do século XIX e início do século XX (o que provocou a Primeira Guerra Mundial) não substituiu o passado da África pelo passado da Europa Ocidental. Foi assim, também, na América do Sul: 500 anos de regimes coloniais por oficiais peninsulares e, desde os anos 1900, por elites de crioulos e mestiços, não apagaram a energia, a força e as memórias do passado indígena (comparemos com questões contemporâneas na Bolívia, Equador, Colômbia, no sul do México e na Guatemala), assim como não foram apagadas as histórias e memórias das comunidades afrodescendentes no Brasil, na Colômbia, no Equador, na Venezuela e no Caribe insular. (MIGNOLO, 2017, p.03)

Ainda que muitas etnias tenham sido dizimadas, e alguns povos vivam um processo de reafirmação étnica, o estado do Amazonas possui a maior população declarada indígena do país, com 168,7 mil, segundo o Censo do IBGE/2010. O total de declarados no país foi de 896,9 mil, 305 etnias e 274 idiomas. Impossível desconsiderar esse aspecto em qualquer análise que se relacione à cultura local.

Por outro lado, não se trata de desvalorizar o avanço conquistado, sobretudo pelas lutas das mulheres, na garantia do direito à creche, inserido no texto constitucional. $\mathrm{O}$ que quero destacar é a visão parcial, de um olhar que escapa à dimensão da multiplicidade étnica presente no país, que permanece sendo escamoteada. Isso é demonstrado em vários momentos da história, desde o início da organização da educação escolar no estado do Amazonas, quando identifiquei, na contradição do discurso referente à educação, a explicitação dos interesses para implantação do projeto de modernidade intencionado. $\mathrm{O}$ discurso oficial da época ilustra a construção desse projeto, a partir da fala do Presidente da Província, Ephigenio Ferreira de Salles ${ }^{3}$ :

\footnotetext{
${ }^{3}$ As pesquisas foram realizadas nos Relatórios e Mensagens proferidas pelos presidentes/governadores da província/estado, na Assembleia Legislativa do Estado do Amazonas, no site http://www.crl.edu/ptbr/brazil/provincial, que reúne importantes
} 
Ademais, convém lembrar que a vida quase nômade do extrator, a movimentar-se conforme a época do seu trabalho, ora nos povoados, ora no seio das florestas, onde emprega sua atividade, forçará a contingência de interromper sempre o ensino a seus filhos. Há localidades que se despovoam durante três ou quatro mezes, em cada anno, devido a esse fenômeno da existência chrematistica do seringueiro ou do castanheiro. Quando a população sertaneja do Amazonas estiver presa ao sólo, pela agricultura ou pela criação, como em parte se vae realizando; quando a visão tentadora da floresta virgem deixar de ser essa miragem de tantos milhares de paes de família, para que estes se encantonem á volta das escolas, então e só então a frequência escolar, na sua percentagem superior a $80 \%$, será a mais fagueira realidade, como acontece no sul do paiz. (RPAM 14/07/1928, p. 67-68)

A educação dos povos da Amazônia era incompatível com os interesses do projeto de modernidade vislumbrado. Assim, matricular as crianças na escola parecia ser, estrategicamente, a forma mais eficaz de manter a população com sua peculiaridade, "presa" na cidade e preparada para atuar como mão de obra de baixo custo, como vai ocorrer mais adiante.

A estratégia discursiva das autoridades locais, a respeito da preocupação com a educação das crianças, é desconstruída pelas evidências histórias, em que, quase um século depois, a despeito da legislação, as vagas necessárias para atender a todas as crianças são inexistentes.

A interferência na cultura local ocorreu sempre que houve interesses políticos e econômicos das classes hegemônicas, como foi o caso da implantação da Zona Franca de Manaus, em 1967, como identificou Spindel, (1987), em pesquisa realizada sobre a formação das mulheres operárias:

documentações digitalizadas do Poder Executivo brasileiro, do período de 1830 a 1930. Acesso em: 14 set. 2019. 
[...] era preciso transformar em exército industrial de reserva um excedente apenas latente. Tratava-se de populações de origem indígena miscigenadas e apenas primariamente aculturadas, inseridas numa economia de subsistência e agrícola extrativa intermitente, espalhados por uma imensa região de rios e florestas. Excluindo Manaus, os núcleos urbanos eram e são muito poucos e de baixíssimo grau de urbanização. (SPINDEL, 1987, p.4)

Torres (2011) atribui o histórico descaso do Estado brasileiro à região, por se tratar de uma área com extensa população indígena, afirmando que:

É recente o olhar do governo central do Brasil para a Amazônia, pois até a década de 70 do século XX o Estado brasileiro não via necessidade de direcionar políticas públicas para a Amazônia, porque é uma região preponderantemente indígena, cujos habitantes sempre foram vistos de forma preconceituosa como seres exóticos e indiferentes ao progresso. (TORRES, 2011, p.114)

As investidas contra a cultura dos povos que ocupavam e ocupam ainda o território amazônico continuam ocorrendo, pela ameaça que significa aos interesses do capital. Uma cultura permeada pela ancestralidade dos povos originários, que resiste aos interesses colonizadores precisa ser extinta, por contradizer a sociedade de consumo como única possibilidade de vida. Nesse sentido, pensar a luta por creche ou a falta dela, pelos estudos da colonialidade, mostrou-se revelador das diferentes formas de dominação e, consequentemente, resistências.

Quanto a isso, vale ressaltar que, a despeito da imagem construída e disseminada pelos colonizadores dos povos originários como indolentes e com pouca inteligência, sempre houve resistência. A condição de subalternidade imposta aos povos da Amazônia não se deu sem que lutas intensas fossem e continuem sendo travadas. 


\section{Entre as lutas das mulheres, educação das crianças pequenininhas}

Analisar os índices de matrículas na creche isolados, sem considerar a história das mulheres amazonenses, a luta pela vaga na creche parece secundarizada, não representando uma causa priorizada por essas mulheres. Nesse sentido, reitero a atenção referente às questões étnicas, sobretudo da cultura indígena, população expressiva na origem da cidade de Manaus, desde sua fundação, como descreve Sampaio (2009):

Em termos demográficos, os dados demonstram o caráter multiétnico das principais cidades amazônicas; a maioria de sua população era não-branca. Em 1787, Belém possuía uma população composta por $38 \%$ de brancos, $11 \%$ de "pretos, índios e mestiços" e $51 \%$ de escravos. Na capitania do Rio Negro, por seu turno, havia uma decisiva maioria indígena; em 1785, 9\% são livres, 3\% são escravos e 88\% são índios. (SAMPAIO, 2009, p.28)

Foi nesse contexto da ancestralidade indígena, presente na cultura manauara, que busquei conhecer a pressão pela vaga na creche, por parte das mulheres, na reivindicação do direito à educação das crianças pequenininhas. As respostas e o silêncio das mães nas entrevistas, quando perguntei o que as crianças fazem numa creche, confirma a pesquisa de Mafra, (2014), acerca da noção de creche das mães, na cidade de Manaus: "[...] essas mulheres não tiveram nenhuma experiência direta com esse equipamento, portanto, não sabem falar com total segurança nem sobre o funcionamento e nem sobre as condições de atendimento numa creche." (MAFRA, 2014, p.85). Das doze mães que entrevistei, somente uma frequentou creche quando criança, pois morava numa comunidade formada por trabalhadoras/es de uma empresa, fora da cidade de Manaus, que oferecia Educação Básica para as/os filhas/os das/os funcionárias/os. 
Além da noção de creche construída pelas mães, há diferenças identificadas nas mulheres manauaras que precisam ser consideradas. Elizabeth Agassiz ${ }^{4}$ fez a seguinte descrição a respeito das mulheres da região, a partir de sua visão eurocêntrica, mas com elementos importantes para análise do processo de resistência à colonialidade imposta aos povos da Amazônia, sobretudo às mulheres:

Eis pessoas de respeitável condição, embora de sangue índio, acima de serem necessitadas, vivendo com facilidade e, relativamente ao seu meio, quase ricas; pessoas entre as quais, por conseguinte, se esperaria encontrar o conhecimento das leis mais simples da moral. Pois bem: quando me apresentaram a moça, como eu lhe pedisse notícias do pai, pensando que fosse o capitão ausente, a mãe me respondeu sorrindo e com a maior simplicidade: Não tem pai; é filho da fortuna. Por sua vez a moça me mostra os seus filhinhos, duas criaturinhas um pouco menos escuras que a mãe, e, à minha pergunta se o pai também estava no exército deu a mesma resposta ingênua: Não tem pai. É habitual que as mulheres índias de sangue mestiço falem a cada ins tante de seus filhos sem pai; isso num tom sem queixa nem tristeza, e, pelo menos na aparência, sem qualquer consciência de vergonha e de culpa, como se o marido estivesse morto ou ausente [...] Quase nunca as crianças sabem coisa alguma sobre seus pais. Conhecem a mãe porque sobre ela recaem os cuidados e toda a responsabilidade, mas ignoram quem seja seu pai, e, realmente, não creio que à mulher ocorra a ideia de que ela e seus filhos tenham qualquer direito sobre tal homem. (AGASSIZ, 1975, p. 165-66).

Para Oliveira (2014), em seus estudos acerca da questão no município de Tefé - AM, esclarece que

\footnotetext{
4 "Dentre a produção científica dos naturalistas que passaram pela Amazônia, no século XIX, o livro Viagem ao Brasil: 1865 - 1866 apresenta uma diferença importante em relação às produções de outros naturalistas, como Spix e Martius (18171820), Bates (1848-1859), Wallace (1848-1852) - a presença de uma mulher como coautora, Elizabeth Carey Agassiz." (RUFINO; RUFINO, 2011, p.16)
} 
[...] existe a ausência demarcada pelas estruturas históricas da organização familiar e papéis de gênero, porém a mulher nesta própria estrutura sempre teve que se articular no cuidado com a prole, dando-as assim, vigor de cuidarem das/os filhas/os com ou sem os parceiros. Na Amazônia é preciso levar em conta as organizações familiares e as atribuições da sexualidade, que nos direcionam a outras dimensões na forma de receber um filho da mãe, diferente de outras regiões do país. (p.17)

[...]

Em determinados momentos da história da Amazônia, coube à mulher mãe o compromisso e as estratégias para os cuidados com a criança sem a presença do parceiro, seja pela questão econômica, seja pelo abandono, etc. Porém as formas de organização familiar amazônica têm a peculiaridade do comum em que, as famílias extensas e comunitárias estão prontas para receber e cuidar dessa/e filha/o da mãe. (p.55)

Costa (2005), investigando a mulher na Amazônia, acrescenta que algumas peculiaridades que caracterizam as mulheres da região estão relacionadas à cultura ancestral indígena, pois

[...] a influência da religião católica, a despeito de ser hegemônica na região, não conseguiu impor seus padrões de moralidade, dada a influência indígena, condições de isolamento, distribuição da população e peculiaridades do processo de colonização e dominação em áreas de fronteira. (COSTA, 2005, p.140)

Para Lugones (2008), a colonialidade do poder engendra a colonialidade de gênero. Assim, as desigualdades são produzidas e reproduzidas também nas relações desiguais entre homens e mulheres colonizados, em que a mulher passa a ser inferiorizada pelo homem, que vive em condição similar de exploração. A mesma situação ocorre entre as mulheres exploradas, em que a mulher negra e a indígena são inferiorizadas. Um alerta para o perigo de fortalecer o feminismo hegemônico, que não dá conta de dialogar com as diferenças, dividindo as excluídas e fragilizando a luta. Lugones (2008) aponta para a segrega- 
ção entre as categorias que, fragmentadas, geram outras formas de exclusão, demonstrando a importância da análise interseccional.

\section{Considerações finais}

O estudo possibilitou aprofundar o conhecimento acerca das relações que foram sendo construídas no decorrer do processo de colonização, que resvala de alguma forma na situação que se observa na atualidade, incidindo no abismo existente entre quantidade de crianças e o número de vagas criadas para atender à demanda. As interrogações construídas acerca da falta de reivindicação das mães por creches para suas/seus filhas/os, por mulheres que foram protagonistas de incessantes lutas, produzindo historicamente a vida, na resistência às relações de dominação, deram espaço para outras interrogações relacionadas ao fortalecimento da desigualdade de gênero e sua vinculação com a manutenção da hegemonia capitalista.

A perspectiva inicial da pesquisa pautava uma reflexão isolada, sem a percepção de que se tratava de questões periféricas, relacionadas entre si, que foram produzidas pela colonialidade. Observei as diferenças que caracterizam um país pluriétnico, em que, embora a cultura dos povos originários esteja fortemente expressa no cotidiano, são invisibilizadas. Nesse contexto das diferenças, a ideia de cuidado e educação de crianças pequenininhas que constam na legislação vigente não deu conta das formas de cuidar e educar vislumbradas pelos povos que, mesmo à revelia, mantêm sua ancestralidade, ainda que, sob efeito das forças produtoras da dominação, atuando na construção das subjetividades dos colonizados.

Nesse sentido, é preciso refletir acerca das condições em que vivem as crianças nos espaços urbanos, onde as mulheres, mães de crianças pequenininhas, estão no trabalho, em cidades nas quais as creches não foram criadas. Cenário que deixa as crianças e mães em situação de vulnerabilidade, como constatei durante a imersão no campo de pesquisa. As mães, desprovidas dos equipamentos sociais necessários, e tendo que garantir a subsistência da família, criam estratégias de 
educação e guarda para as filhas e os filhos, que nem sempre são condizentes com o Estatuto da Criança e Adolescente (Lei no 8.069, de 13 de julho de 1990), como deixar as/os filhas/os com irmãs ou irmãos mais velha/os, também crianças, com poucas ou nenhuma chance de romper com o ciclo das condições de subalternização imposta.

A pesquisa demonstrou como a ausência de um direito, nesse caso o da creche, acarreta outros que colocam a vida de mulheres e crianças em condições sub-humanas. Sem ter onde deixar as/os filhas/os as mães se submetem ao trabalho informal, sem os direitos trabalhistas e acesso aos benefícios sociais, destinados à mulher grávida e após o parto, nos primeiros meses do bebê. Assim, o Estado que não garante o direito à creche às mães, e favorece o trabalho em condições precarizadas, sem carteira assinada, é o mesmo que exige a comprovação na carteira de trabalho, para acessar o direito aos benefícios sociais, enquanto precisa cuidar do bebê recém-nascido. O Estado não ofereceu as condições para que a mãe trabalhe e a penaliza, excluindo-a dos direitos sociais, garantidos às mulheres.

Diante das condições materiais das mães para produzir sua existência, elas afirmam acreditar na creche como uma alternativa de mobilidade social. Colocar a criança na creche corresponde à preparação para a/o filha/o ser bem sucedida/o no Ensino Fundamental. A creche não é um lugar compreendido para as crianças vivenciarem suas infâncias, mas para aprenderem as letras, escreverem o nome, serem escolarizadas. As mães compreendem a creche como esse espaço preparatório que, se garantido às suas crianças, poderá ajudá-las na aprendizagem dos conteúdos escolares.

Na percepção das mães quanto ao direito das crianças à educação e a compreensão do espaço da creche como preparatório, é possível perceber os efeitos da colonialidade na reprodução das subjetividades. Assim, descolonizar o pensamento e atuar contra o feminismo hegemônico são formas de desarticular a colonialidade e dar passos importantes na direção dos avanços sociais, reconhecendo a condição pluriétnica do povo brasileiro, em todos os campos, inclusive do direito, valorizando a cultura dos povos originários, abrindo espaços para o 
diálogo sobre as formas de educar as crianças pequenininhas. Para isso, precisa-se romper com o que divide os grupos sociais subalternizados, pertencentes ao mesmo processo de exclusão, e dialogar com as diferenças que nos constituem, a fim de pensar quais são as alternativas de superação e construção da autonomia dos povos que inventam todos os dias formas de resistência na Amazônia.

\section{Referências}

AGASSIZ, Louis; AGASSIZ, Elisabeth Cary. Viagem ao Brasil: 18651866. Belo Horizonte: Itatiaia, São Paulo, 1975.

BARATA, Joaquina. Etnias amazônicas: confrontos culturais e intercorrências no campo jurídico. Ser. Soc., São Paulo, n 133, set/dez, p. 501-514,2018. < http://dx.doi.org/10.1590/0101-6628.156> Acesso em: 12 dez. 2019.

BRASIL, Constituição (1988). Constituição da República Federativa do Brasil. Brasília, DF: Senado, 1988.

. Lei $\mathrm{n}^{\circ}$ 8069, de 13 de julho de 1990. Dispõe sobre o Estatuto da Criança e do Adolescente e dá outras providências. Diário Oficial da República Federativa do Brasil, Brasília, DF, 16 jul. 1990. Disponível em: <http://www.planalto.gov.br/ccivil 03/LEIS/ L8069.htm\#art266> Acesso em: $18 \mathrm{dez} .2018$.

. Lei n 9394, de 20 de dezembro de 1996. Estabelece Diretrizes e Bases da Educação Nacional. Diário Oficial da União, Brasília, DF, 1996.

. IBGE- Instituto Brasileiro de Geografia e Estatística. Pesquisa Nacional por Amostra de Domicílios: síntese de indicadores 2009. Rio de Janeiro, 2010. Disponível em: <www.ibge.gov.br $>$. Acesso em 12 jan. 2018.

COSTA, Heloísa Lara Campos da. As mulheres e o poder na Amazônia. Manaus: EDUA, 2005. 
LIMA, Deborah de Magalhães. A construção histórica do termo caboclo sobre estruturas e representações sociais no meio rural amazônico. Novos Cadernos NAEA, Belém, v. 2, nº 2, p.5-32, 1999.

LUGONES, María. Colonialidad y género. Tabula Rasa, n. 9, p. 73101, jul./dez. 2008

. Rumo a um feminismo descolonial. Revista Estudos Feministas, Florianópolis, v. 22, n. 3, p. 935-952, set. 2014.

MAFRA, Ivanilde dos Santos. O direito à educação da criança pequena na cidade de Manaus: noções presentes entre as mães de classes populares. 125 f. 2014. Dissertação (Mestrado em Educação). Universidade Federal do Mato Grosso do Sul- Corumbá, 2014.

MIGNOLO, Walter D. Histórias locais- Projetos globais: colonialidade, saberes subalternos e pensamento limiar. Tradução de Solange Ribeiro de Oliveira: Belo Horizonte: ED UFMG, 2003.

A colonialidade de cabo a rabo: o hemisfério ocidental no horizonte conceitual da modernidade. In: LANDER, Edgardo (Org). A colonialidade do saber: eurocentrismo e ciências sociais. Perspectivas latino-americanas. Buenos Aires: CLACSO, p. 33- 49, set. 2005.

. Colonialidade, o lado escuro da modernidade. Trad. Marco

Oliveira. Revista Brasileira de Ciências Sociais, v. 32, n.94, p. 1-17, jun. 2017.

OLIVEIRA, Rônisson de Souza de. As mães dos "filhos da mãe" em Tefé/Am: a ilusão dos impactos da ausência. 2014. 140 f. Dissertação (Mestrado em Sociologia) - Curso de Sociologia, Instituto de Ciência Humanas e Letras, Universidade Federal do Amazonas, Manaus, 2014. QUIJANO, Aníbal. Colonialidade do poder, eurocentrismo e América Latina. In: LANDER, Edgardo (org). A colonialidade do saber: eurocentrismo e ciências sociais. Perspectivas latinoamericanas. Buenos Aires: CLACSO, setembro 2005, p. 107-130.

. Colonialidaddel poder y Claficiación Social. In: CLÍMACO, Danilo Assis (Org.) Cuestiones y Horizontes: de la dependencia histo- 
rico-estrutural a la colonialidad/descolonialidad del poder. Buenos Aires: CLACSO, 2014.

RUFINO, Márcia Regina Calderipe Farias; RUFINO, Dilton Mota. Elizabeth Agassiz e a Expedição Thayer: uma reflexão sobre a ciência e gênero na Amazônia. In: TORRES, Iraildes Caldas; SANTOS, Fabiane Vicente dos (orgs.). Intersecção de Gênero na Amazônia. Manaus: EDUA, p. 16- 40, 2011.

SAMPAIO, Patricia Melo. Amazônica: fronteiras, identidade e história. Revista Ciência e Cultura. v. 61,n 3, São Paulo, p.26-29, 2009. Disponível em: < http://cienciaecultura.bvs.br/pdf/cic/v61n3/pdf $>$ Acesso em: 14 maio 2019.

SANTOS, Fabiane Vicente dos. "Brincos de ouro, saias de chita": mulher e civilização na Amazônia segundo Elizabeth Agassiz em Viagem ao Brasil (1865-1866). História, Ciências, Saúde - Manguinhos, Rio de Janeiro, v. 12, n. 1, p. 11-32, jan.-abr. 2005.

SEGATO, Rita Laura. Las estructuras elementales de la violencia. Ensayos sobre género entre la antropología, el psicoanálisis y los derechos humanos. Bernal: Universidad de Quilmes, 2003

. Gênero e Colonialidade: em busca de chaves de leitura e de um vocabulário estratégico descolonial. E-Cadernos Ces (Online), V. 18, p. 1-5, 2012. Disponível em: <https://journals.openedition.org/ eces/1533> Acesso em: 29 jun. 2020

. El sexo y la norma: frente estatal, patriarcado, desposesión, colonidad. Revista Estudos Feministas, Florianópolis, v. 22, n. 2, p. 675-686, maio 2014.

SPINDEL, Cheywa Rojza. Formação de um novo proletariado: as operárias do distrito industrial de Manaus. Revista Brasileira de Estudos da População. São Paulo, v. 4, nº2, p. 138, jul/dez. 1987.

TORRES, Iraildes Caldas; SANTOS, Fabiane Vicente dos. (orgs). Intersecção de Gênero na Amazônia. Manaus: Edua, 2011. 


\section{A Formação social da Amazônia sob a perspectiva de gênero.}

Anais do Seminário Internacional Fazendo Gênero 8- Corpo, Violência e Poder, Florianópolis, agosto de 2008. Disponível em:

$<$ http:www.fazendogenero.ufsc.br/8/sts/ST19/

Iraildes Caldas Torres 19 pdf > Acesso em: 12 abr. 2017. 
